\section{International Scientific Journal Theoretical \& Applied Science}

p-ISSN: 2308-4944 (print) e-ISSN: 2409-0085 (online)

Year: 2017 Issue: 08 Volume: 52

Published: $30.08 .2017 \quad$ http://T-Science.org
Asli Khanguseyn Kazymova

Doctor of Philosophy in Economics, Senior lecturer of the department "Regulation of Economics" Azerbaijan State Economic University, Azerbaijan Republic nauka-xxi@mail.ru

SECTION 19. Management. Marketing. Public administration.

\title{
MODELING OF RAW MATERIAL SECURITY OF NON-PERFECT SECTORS OF THE ECONOMY OF AZERBAIJAN IN THE CONDITIONS OF GLOBAL CHANGES
}

Abstract: The modeling of raw materials supply of the non-oil sectors of the Azerbaijani economy in the conditions of global changes are studied in the article. The level and main trends of development of the non-oil sector of the country's economy in the current conditions are analyzed. The problems of resource availability and the level of adequacy of natural reserves of a number of non-oil sectors of the country's economy are considered. The importance of developing the quality of competitive and powerful sectors of the non-oil sector, such as the chemical and petrochemical, metallurgical and construction sectors of the national economy are noted. The views that modernization and updating of the basic mechanisms and practical tools of the non-oil sector of the country's economy are required in the context of the growth of global threats and changes are generalized.

Key words: the non-oil sector of the economy of Azerbaijan, the modeling of the raw materials supply of the non-oil sector, global economic threats, the metallurgical complex of Azerbaijan, the chemical and petrochemical complex of Azerbaijan, the construction sector and the production of building materials of Azerbaijan.

Language: Russian

Citation: Kazymova AK (2017) MODELING OF RAW MATERIAL SECURITY OF NON-PERFECT SECTORS OF THE ECONOMY OF AZERBAIJAN IN THE CONDITIONS OF GLOBAL CHANGES. ISJ Theoretical \& Applied Science, 08 (52): 85-88.

Soi: http://s-o-i.org/1.1/TAS-08-52-13 Doi: crossef https://dx.doi.org/10.15863/TAS.2017.08.52.13

\section{МОДЕЛИРОВАНИЕ СЫРЬЕВОЙ ОБЕСПЕЧЕННОСТИ НЕНЕФТЯНЫХ СЕКТОРОВ ЭКОНОМИКИ АЗЕРБАЙДЖАНА В УСЛОВИЯХ ГЛОБАЛЬНЫХ ИЗМЕНЕНИЙ}

Аннотация: В статье исследовано моделирование сырьевой обеспеченности ненефтяных секторов экономики Азербайджана в условиях глобальных изменений. Анализированы уровень и основные тенденции развития ненефтяного сектора экономики страны в нынешних условиях. Рассмотрены проблемы ресурсообеспеченности и уровень адекватности природных запасов ряда ненефтяных секторов экономики страны. Отмечена важность развития качества конкурентоспособных и мощных отраслей ненефтяного сектора, таких как химического и нефтехимического, металлургического и строительного сектора национальной экономики. Обобщены мнения в том, что требуется модернизация и обновление основных механизмов и практичных инструментарий ненефтяного сектора экономики страны в контексте роста глобальных угроз и изменений.

Ключевые слова: ненефтяной сектор экономики Азербайджана, моделирование сырьевой обеспеченности ненефтяного сектора, глобальные экономические угрозы, металлургический комплекс Азербайджана, химических и нефтехимический комплекс Азербайджана, строительный сектор и производство строительных материалов Азербайджана.

\section{Introduction}

В связи с интенсификацией трансформации основных механизмов национальной экономики и отдельных еe секторов Азербайджана в условиях глобальных изменений и глобальных экономических угроз постоянно идет давление на существующие механизмы и практичные инструментарии развития ненефтяных секторов экономики страны. Вопрос очень актуальный и даже болезненный, дело в том что, в связи с падением цен на нефть на мировых рынках за последние годы резко снизился валютный доход 
Азербайджана, что отрицательно повлияло на рост национальной экономики. Исходя из этих соображений, руководство страны взяло серьезный и ускоренный курс на перевод тяжести экономики страны именно на плечо ненефтяного сектора экономик, тем самым обеспечило минимизацию негативных последствий финансовых и экономических кризисов в последние годы, и как было отмечено, отрицательных действий после падения цен на нефть, которая является локомотивом экономики Азербайджана после восстановления независимости страны с расспадом бывшего СССР. У Азербайджана на это имеются все основания, так как, по мнению ведущих ученых страны, во главе с академиком А.Надировым, который считает, что Азербайджан имеет достаточные природные богатства и экономические ресурсы для диверсификации своей национальной экономики и ускоренного развития ненефтяных секторов экономики страны в нынешних условиях[1]. Более того, моделирование развития ненефтяных секторов экономики страны безусловно, больше всего зависит от адекватности ресурсообеспеченности основными видами сырьевых ресурсов для развития того или иного сектора экономики страны, особенно ненефтяных секторов, прежде всего, конкурентоспособных секторов экономики (металлургический, химический и нефтехимический, строительный и прочие сектора). Дело в том, что Азербайджан имея достаточный ресурсный потенциал для диверсификации структуры национальной экономики, обладает реальными возможностями для осуществления модернизации и интенсификации отдельных секторов экономики страны, ну и безусловно, важных сфер ненефтяного сектора, которые способны производить достаточно конкурентоспособную национальную продукцию и внести серьезный вклад в рост экономики страны. Профессора Ш.Гаджиев, Р.Гасанов, А.Аллахвердиев, Т.Алиев и Ш.Алиев справедливо отмечают, что у Азербайджана, наряду с сырьевой обеспеченностью и ресурсным потенциалом, есть реальные шансы успешные преодолеть макроэкономические трудности в нынешних условиях и сформировать более устойчивые, прочные, иммунитетные механизмы модели экономического развития в условиях роста глобальных экономических угроз и трансформаций мирохозяйственной системы[2; 3 ; 4; 5; 6]. Однако, к большому сожалению, в последние годы, несмотря на проводимые полномасштабные работы и мероприятия по повышению роли и удельного веса ненефтяного сектора экономики страны в общем объеме национальных продуктов, рост ожидаемых результатов не обеспечивает динамичность развития национальной экономики и не может компенсировать потерянные валютные средства от понижения цен на нефть. Кроме того, несмотря на имеющийся экспортный потенциал, основные ненефтяных секторы экономики Азербайджана в общей доли экспорта имеют низкие показатели. Например, металлургическиая и химическая промышленности в общем объеме экспорта не имеют даже одной доли процента. В наличии мощного экспортного потенциала сельскохозяйственной продукции и агросектора пока не обеспечена их реализация на прогнозируемом уровне[7].

\section{Materials and Methods}

Мы хотели бы обратить внимание на проблемы обеспеченности ряда ненефтяных секторов экономики, которые, на наш взгляд, имеют реальные возможности для оказания положительного внимания на диверсификацию и рост национальной экономики в ближайшей перспективе. Одним из важных ненефтяных секторов экономики страны является химическая и нефтехимическая промышленность страны, которая способна выработать более продуктивную, различных видов, инновационную продукцию и обеспечить серьезный рост экономики страны[8; 9]. Химический и нефтехимический сектор страны имеет огромный потенциал по обеспеченности основными видами сырьевых ресурсов и их запасов[10]. Дело в том, что с ростом добычи нефти и природного газа, безусловно, повышаются возможности увеличения с необходимыми первичными сырьевыми компонентами нефтегазоперерабатывающих предприятий и в дальнейшем для адекватного обеспечения основных технологический установок крупных химических и нефтехимических предприятий. В Азербайджане имеется 71 нефтегазовых залежей, из них 43 находится на суше и 28 в шельфе Каспийского моря. Подтвержденные запасы нефти с учетом различных прогнозов международных организаций, институтов и в том числе официальных структур Азербайджана запасы нефти в шельфовой зоне национального сектора Каспийского моря находится примерно в количестве 4 млрд. тонн. Более того, запасы природного газа считаются довольно серьезно перспективными и выгодными с учетом реализации международных энергетических проектов, в том числе доставки азербайджанского природного газа в европейские страны[11]. Запасы природного газа с учетом прогнозов оцениваются на уровне 7 трлн. куб. метров. Запасы отдельных основных морских газовых месторождений и запасов, например «Шахдениз» 
оцениваются на уровне 1,2 трлн. куб. метров, «Банка Дарвина» - 400 млрд. куб. метров, «Умид» - 200 млрд. куб метров, «Абшерон» - 350 млрд. куб. метров и так далее. В связи с ростом добычи природного газа появляются реальные возможности для направления части добытого газового сырья на перерабатывающую сеть и создать мощную, конкурентоспособную и в то же время крупные производительные газоперерабатывающие предприятия, которые в свою очередь будут способны обеспечить крупными и беспрерывными потоками сырьевых ресурсов предприятий химической и нефтехимической промышленности страны. Кроме минеральных углеводородных ресурсов и запасов в Азербайджане, для развития химической и нефтехимической промышленности имеются мощные запасы по производству йода и кальцинированной соды[12]. Дело в том, что территория Абшеронского полуострова и Нефтчалинского района насыщена горными нефтяными истоками, которые являются сырьем для производства йода. Кроме того, на территории Нахчыванской Автономной Республики находятся крупные соляные запасы, в количество 730 млн. тонн промышленного значения, которые являются исходным сырьем для организации производства кальцинированной соли[13].

Следующая более перспективная и продуктивная отрасль национальной экономики ненефтяной сферы считается металлургическая отрасль. Этот комплекс имеет традиционную историю и сильно развитую инфраструктуру, кадровый потенциал. Но самое главное, у отрасли существуют мощные и большие рудные запасы в Азербайджане и прочие природные ресурсы для развития металлургической промышленности, причем оба ее главных направления деятельности - черная и цветная металлургия. Отметим, что только в одних залежах глины бентонита в Газахском районе запасы промышленного назначения имеются свыше 100 млн. тонн, которые считаются одним из главных сырьевых ресурсов в развитии черной металлургии. Кроме того, в главном рудном центре Азербайджана - в Дашкесенском районе имеются залежи флюсизвестняка в количестве 50 млн. тонн промышленного назначения. В Нехрамском залежах Нахчыванской Автономной Республики страны обращают внимание на доломитные залежи с запасами свыше 4 млн. тонн. Кроме того, в Дашкесене существуют залежи алунита, которая являются основным видом сырьевой базы для алюминиевой промышленности. Достаточные запасы для развития горнообогатительной промышленности могут обеспечить полноценную диверсификацию национальной экономики Азербайджана и ускорить развитие одной из важных сфер ненефтяного сектора - металлургического комплекса страны[14]. Отметим, что металлургическая отрасль в Азербайджане была сильно развита еще в советские времена. В Сумгайыте функционировал крупный трубопрокатный завод, где работало почти 10 тысяч человек. А ныне основные тяжести мощности металлургического комплекса сконцентрированы, наряду с Сумгайытским промышленным центром, в другом крупном промышленном центре страны - в городе Гянджа, где заканчивается строительство крупного металлургического комплекса, в том числе прокатного цеха, где будут производить продукцию и полуфабрикаты для дальнейшего изготовления разного вида металлургических изделий, труб и других видов продукции. Все эти стратегические задачи и приоритетные направления деятельности являются главной стратегической целью промышленности тяжелого машиностроения в ближайшей перспективе[15]. Более того, в Стратегической Дорожной Карте по перспективам национальной экономики Азербайджанской Республики особое внимание обращается на развитие промышленности тяжелого машиностроения и намечается повышение результативности данной отрасли до серьезного уровня[16].

Одним из важных отраслей национальной экономики страны, который имеет огромные запасы сырьевых ресурсов, является строительный сектор. В последние десятилетия в Азербайджане происходил процесс «строительного бума». Было построено сотни крупных заводов, промышленных объектов, тысячи инфраструктурных объектов и сооружений, дорог, мостов и жилых массивов. Все эти процессы потребовали интенсификации развития строительного сектора, особенно производства строительных материалов. В Азербайджане имеются более 240 строительных залежей промышленного назначения и нерудных сырьевых залежей для производства строительных материалов. В их числе огромные запасы и сырьевые залежи цемента, известняка, гипс, мел, глины, облицовочного материала, камня и кубика, мрамора, керамита, плит, кирпичей и т.д. Но, к большому сожалению, уровень адекватности и эффективности развития сети предприятий с современными оборудованиями и технологиями, производство строительных материалов в Азербайджане еще не отвечает растущим требованиям нынешних непростых ситуаций в условиях расширения негативных последствий глобализации. Правда, в Азербайджане построено два крупных цементных заводов, однако по другим видам строительных материалов слабо использованы имеющиеся 
природные запасы и сырьевые залежи, которые имеются практически во многих регионах страны, в том числе в Абшеронском полуострове, Гянджа-Газахском экономическом районе и в Нахчыванской Автономной Республике.

\section{Conclusion}

Отметим, что в ближайшей перспективе, ожидается модернизация и обновление основных механизмов и практичных инструментарий поведения деятельности ненефтяных секторов экономики страны, так как они не отвечают основным критериям прироста глобальных экономический угроз и прочих негативных последствий последнего времени. В Азербайджане необходимо обеспечить адекватность развития ненефтяных секторов экономики страны, с учетом опережения негативных последствий известных глобальных отрицательных влияний в том или ином секторе экономики страны. Уровень и развитие деятельности ненефтяного сектора экономики страны должен способствовать обеспечению макроэкономической стабильности в стране, устойчивости и динамичному роста экономики Азербайджана в контексте роста глобальных экономических угроз и основных глобальных изменений в нынешних условиях.

\section{References:}

1. Nadirov A., Muradov SH., Aleskerov A., Nuriyev A., Guseynov T. (2003) Ekonomika Azerbaydzhana. Baku, «Elm», -344 p.

2. Gadzhiyev SH.G. (2011) Identifikatsiya modeli ekonomicheskogo razvitiya Azerbaydzhana. «Geydar Aliyev i strategiya modernizatsii Azerbaydzhana». Baku: Azerneshr, 2011. -708 p.

3. Gasanov R.T. (2012) Osobennosti sotsial'noekonomicheskogo razvitiya sovrmennogo Azerbaydzhana // Nalogovyy zhurnal Azerbaydzhana, №2, 2012. -p.103-108.

4. Allakhverdiyev A.G. (2004) Problemy sovershenstvovaniya makroekonomicheskoy dinamiki i strukturnykh izmeneniy v protsessakh formirovaniya rynochnoy ekonomiki. Avtoreferat diss. d-ra ekon. nauk. Natsonal'naya Akademiya Nauk Azerbaydzhana, Institut Ekonomiki. Baku, 2004. -45 p.

5. Aliyev T.N. (2016) Innovatsionnoye razvitiye promyshlennosti Azerbaydzhana: neftepererabotka, khimiya i neftekhimiya. Moskva-Berlin, «Palmarium», 2016.-232 p.

6. Aliyev SH.T. (2016) Sovremennyye aspekty i napravleniya razvitiya neftekhimicheskogo kompleksa v Azerbaydzhane // Zhurnal Audit, 2016, №3.- p. 41-45.

7. (2017) Azerbaydzhan v tsifrakh, Baku.- 286 p.

8. Aliyev T.N., Babayev M.T. (2011) Aktual'nyye ekonomicheskiye problemy otrasli: neftepererabotka i neftekhimiya. Baku, «Nauka i obrazovaniye».-346 p.
9. Aliyev T.N. (2014) Organizatsonnoekonomicheskiye aspekty innovatsionnoy deyatel'nosti malykh i srednikh predpriyatiy $\mathrm{v}$ Azerbaydzhane // Informatsiya i innovatsii, №3-4, Moscow, 2014.-p. 106-116.

10. (2017) Poleznyye iskopayemyye Azerbaydzhana. Obshchestvo Geografii Azerbaydzhana. Available: http://www.gsaz.az. (Accessed: 10.08.2017).

11. Gasanov A. (2017) Uchastiye energeticheskikh resursov Kaspiyskogo basseyna i Yuzhnogo Kavkaza v energeticheskoy bezopasnosti Yevropy. Available: http://az.strategiya.az. (Accessed: 10.08.2017).

12. (2017) Prirodnyye zapasy Azerbaydzhana. Available: http://kayzen.az

13. (2017) Prirodnyye bogatstva Azerbaydzhana. Available: $\quad$ http://azecology.az/az/elaqe (Accessed: 10.08.2017).

14. Shukyurov A. (2017) Sektor mineral'nosyr'yevykh resursov stoit $\mathrm{v}$ tsentre izmeneniy, proiskhodyashchikh $\mathrm{v}$ mirovoy ekonomike. Available:

http://az.strategiya.az/old/?m=xeber\&id=13955 (Accessed: 10.08.2017).

15. (2017) Strategicheskiye tseli v tyazheloy promyshlennosti i mashinostroyenii. Available: http://www.marja.az. (Accessed: 10.08.2017).

16. (2016) Strategicheskiye dorozhnyye karty po perspektivam natsional'noy ekonomiki Azerbaydzhanskoy Respubliki. Utverzhdeno Ukazom Prezidenta Azerbaydzhanskoy Respubliki ot 6 dekabrya 2016 goda. 